\title{
Research on the Reform and Construction of Large - scale System in Colleges and Universities
}

\author{
Chaohui $\mathrm{Ma}^{1, \mathrm{a}}$ \\ ${ }^{1}$ Dianxi Science and Technology Normal University, Lincang, Yunnan, China, 677000 \\ aemail,
}

\begin{abstract}
Keywords: Large - Scale System; Colleges; Existing Problems; Follow the Original Principle;
\end{abstract} Reform and Construction Measures

\begin{abstract}
With the promotion and popularization of quality education and the reform of new curriculum standards, the traditional educational concepts and teaching modes in schools at all levels in our country need to be further improved. For colleges and universities, it is necessary to strengthen the reform of large-scale system, to optimize the functions of various departments in colleges and universities, improve the level of service and quality, and then ensure that teaching activities to carry out better. This article mainly deals with the problems in the process of the reform and construction of colleges and universities in the process of reform and construction of colleges and universities, the principles that need to be followed in the reform and construction of colleges and universities, and the effective measures to strengthen the reform of colleges and universities analysis and research, which accelerate the promotion of large-scale reform and construction of colleges and universities to provide a valuable reference.
\end{abstract}

\section{Introduction}

From the beginning of the 1990s, the large-scale expansion and merger of institutions of higher learning effectively promoted the development and progress of higher education in our country, which also greatly increased the function and scale of the university. Need to deal with the matter greatly increased, which colleges and universities in the various departments put forward higher requirements. In order to alleviate this phenomenon, colleges and universities are gradually beginning to set up a large number of institutional departments, but before the set because there is no reasonable planning, resulting in the final decline in quality of service, service attitude decline, management efficiency is low, cross, institutional bloated and other issues, limiting the sustainable development of colleges and universities. In view of this phenomenon, colleges and universities must strengthen the merger and streamlining of institutions, optimize the functions of the department, which can be achieved through the reform of the system. In the process of practical application, we need to follow the corresponding reform and construction principles, to avoid the emergence of new problems, to ensure the effectiveness of reform.

\section{The General System of Colleges and Universities}

Most of the system is also known as the majority of the system, is in 2008 by the central government departments put forward and the implementation of a system, refers to the process of setting up the department, the functions and business scope of similar departments centralized management and thus effectively avoid the emergence of bull management, functional cross phenomenon and so on, in improving the efficiency of the formation at the same time, the cost of investment is also greatly reduced, has been in our country at all levels of government departments have been widely used [1]. At present, for the majority of colleges and universities in colleges and universities, there is no clear stipulation in the academic circles, which can be combined with the concept of "academic system". The university system is a kind of combination system and college system. The classification of basic standards is for the discipline, merging, reorganization of the same disciplines and faculty, and the formation of a management [2]. 


\section{The Current Problems in the Process Of Reform and Construction of Large-Scale Colleges and Universities in Colleges and Universities}

At present, although there are already many colleges and universities across the country have been gradually using the majority system, but because there is no reasonable planning and design, at the same time in the understanding and decision-making there are still some errors, resulting in the implementation of the specific effect is not ideal, it is difficult to continue the effective reform of colleges and universities.

Lack of Knowledge. In the process of reforming the university system, it is still deeply influenced by the traditional management concept and management mode. The way of thinking is more backward. If you want to get the expected effect, you need to pay attention to change the idea. But also in the reform and construction, the early and did not make in-depth study and extensive publicity, leading to a lot of people in the consciousness of the full recognition of the reform of the building to the importance and value of the lack of reform of the enthusiasm [3] In addition, the reform of the university system will inevitably need to adjust and reorganize the current departmental arrangements, so that some staff members will think that they will be involved in their own interests, thus hindering the smooth implementation of the reform.

The Difficulty of Reform. At present, in many institutional reform are tending to formalization, its main performance is that although the number of institutions to reduce the set, but the staff, management and other aspects of the content are still to maintain the status quo, which also lost the significance of reform. This is the same problem in the reform of the university system. When the problem is explored, it is necessary to reform it, but when it comes to its own department, it is necessary to think that its own department is indispensable, the difficulty of streamlining is relatively large, and ultimately lead to the reform of the streamlining - expansion - and then streamlined - re-expansion of the vicious cycle, not only difficult to obtain the appropriate reform results, and even increase the cost of expenditure, thereby increasing the difficulty of reform [4 ].

The Difficulty of Integration of Docking Personnel and Departments. In the reform and construction of colleges and universities, the departments and personnel involved are more involved. It is very difficult to merge and reorganize the administrative resources, and it is easy to overlap and cross the power in the process of reform. At the same time, all the staff need to be diverted, which is the reform of the difficult problems, only when all the staff have been extended distribution and placement, to ensure the follow-up work smoothly. Therefore, in the process of reform and construction both need to obtain certain reform effectiveness, but also need to maintain the stability of the internal and external environment.

Supervision Is More Difficult. The main reason for the low efficiency of the government is mainly due to the interests of the sector and the power of the sector, and through the use of the majority of the system reform, we can effectively avoid the various departments between each other, the problem of cross, unify the various departments, will increase the difficulty of supervision. In order to avoid the problem of corruption, it is necessary to strengthen the construction of the mechanism of power supervision and restraint. We must strengthen the construction of the restraint mechanism of power supervision, and make supervision, implementation and decision separation.

\section{The Principles Needed to Follow in the Reform of Colleges and Universities}

Balance the Organization and Tasks. The primary problem in the reform of the university system is that the department with the nature of the work or the main function is close to the office, or the departments are integrated into a department for unified management. The most important thing is the need to combine, reorganize and optimize the department the management function to achieve "downsizing efficiency." But in the adjustment process, does not mean the need to weaken the original service functions of the department, after the implementation of the majority system, can reduce the existing barriers between the various departments, to find the balance between the organization and the task, and then effective the integration of the functions of various departments to further strengthen the teaching services sector functions, enhance service efficiency and 
administrative efficiency [5].

Clear Division of Labor between Each Other to Strengthen Cooperation. In the reform and construction of colleges and universities, the division of labor is clear, strengthen cooperation is an important principle, but also to optimize and improve the basis of university management. The purpose of the main purpose is through the appropriate streamlining and adjustment, to achieve the first service, code of conduct, coordination of operation, the purpose of efficient work, so that the "power and responsibility", the division of functions and responsibilities of departments to be clear, a department can at the same time bear a number of the same or similar functions, and thus effectively prevent the occurrence of each other passing, long management, government and other issues. At the same time, there is a need to strengthen cooperation between each other and ensure that the functions of each department and staff can be fully exploited, and the flexibility in deployment and management is greatly increased.

Adapt the Reform Environment. After the implementation of the reform in the university, the operational mechanisms and responsibilities of the departments need to fully adapt to the reform of the environment, to ensure its flexibility and flexibility, which is in the latter part of the management must follow the main principles [6]. Through flexible management, not only can the department staff from the heavy work of the liberation, but also in the school long-term development of more time and effort, and thus promote the school better development.

Reunification of Uniformity and Efficiency. The reform and construction of large-scale colleges and universities in colleges and universities need to be efficient, standardized and institutionalized, and ensure the work procedures, functions and organizational structure of the latter part of the system. It is necessary to follow the rules and regulations to avoid randomness in the later work. At the same time in the construction process also need to pay attention to the number of teaching services, responsibilities, etc., to be qualified to post to post. In addition, it is necessary to combine the teacher appointment system to ensure that the service department staff can also implement the term system and appointment system to create a competitive environment.

\section{Effective Measures to Strengthen the Reform of Colleges and Universities}

Strengthen the Construction of University Administrative Team. In the construction of the administrative team, the personnel system reform is one of the important issues, must be compatible with the personnel distribution system, and to ensure its rationality and scientific nature, which is to improve the quality of the administrative team basis and premise. As a result of the reform and construction of colleges and universities in the system, will involve the original distribution of benefits, so in the process of reform must ensure that all departments and personnel integration is reasonable, and strictly based on management, research and teaching the actual needs To strengthen the preparation of management at the same time, reduce the management level, in particular, need to attach importance to the leadership of the power and the effective control of posts [7]. In addition, it is necessary to ensure that the staff employment system is reasonable and perfect, make appropriate changes to the employment of the employing staff, and change the relationship between the faculty, the manager and the staff and the school into a "contract" mode, System, so as to be able to fundamentally ensure that the reform effect.

Make a Correct Division of Administrative and Academic Relations. For the two aspects of administrative power and academic power in colleges and universities, it is the two power categories that are independent and mutually influential. At present, the administrative power is higher in colleges and universities, and the academic power is relatively low, but the school as the education and teaching activities the main platform, academic power should be the school's main power, so as to be able to truly achieve the comprehensive development of the school. In order to ensure academic freedom, academic should also be seen as a power to reduce administrative intervention, but it is important to note that if the university is only based on academic power, the value of scholars, teachers and related groups is difficult to get good implementation, which also need to strengthen the administrative power to support and support the full play [8].

Strengthen the Planning of Departments and Functions. In the reform of the university 
system, the most important thing is to combine, reorganize and optimize the management functions of various departments. Through this unified management mode, the functions of various departments in colleges and universities can be fully exploited. With the significantly reduced departments, the barriers between each other are greatly reduced, the teaching services functions can be better completed, and after effective integration, but also further strengthen the teaching services sector strength, improve its service effectiveness and effectiveness. However, in the reorganization and planning of university service departments, on the one hand the need to strengthen the general and comprehensive consideration of the department, on the other hand also need to pay attention to the independence of the department set up and professional, so in the actual planning time, such as qualitative analysis of departmental work, detailed dissection of job content, careful analysis of the various tasks.

Promote Functional Optimization. In order to ensure the effectiveness of reform and construction of large-scale colleges and universities, the most important thing is to adhere to the "clear division of labor, strengthen cooperation" principle, in the actual work to achieve clear responsibilities and responsibilities. Which in the set or reorganization of institutional departments, the need for strict according to different functions, that is, personnel organizations, logistics services, financial supervision, scientific research, teaching and other systems, to rationally establish the appropriate management agencies. If there is a subsidiary in the administrative and functional functions of the organization, the more vague boundaries of the institutional departments, then need to be stripped to ensure that there is no cross between service and management [9]. And in the internal general logistics, scientific research, students, teaching, administration, party groups and other management agencies and personnel need to be different according to the nature of its classification management, and thus effectively avoid the phenomenon of unclear powers and responsibilities, And to promote the further simplification of the multiple leadership structure, and better carry out educational activities.

\section{Conclusion}

In general, the construction of large-scale reform in colleges and universities is an important means to realize the sustainable development of education, which can effectively improve the teaching service and management level and quality. In the process of actual reform and construction, we must first strengthen the construction of the administrative team of colleges and universities to ensure the follow-up reform and construction activities can be carried out smoothly; secondly, the need for administrative and academic relations to make a correct division, the two always maintained between Stability of the state which; once again need to strengthen the planning of departments and functions to improve the effectiveness of the various departments and efficiency; and finally promote the optimization of functions to ensure that the management services can be effectively completed.

\section{References}

[1] Li Rong, Chen Zhigang. "Double first-class" to create the background of the reform of large-scale system construction [J]. Jiangsu Higher Education, 2016,06: 43-46.

[2] Lin Xiang-tian, Fan Li-juan.Study on the Goal Plan and Operation Mechanism of the Reform of the Large Department of Functional Functions in Colleges and Universities [J / OL]. Education and Management, 2014 (04). Http://www.cnki.net/kcms/detail /10.13316/j.cnki.jhem.2014.04.004.html

[3] Chen Daxing. Institutional logic under the university system reform: origin, challenges and forward [J]. Graduate Education Research, 2013,01: 1-6.

[4] Fan Lijuan. Reform of the majority system and the optimization of internal power structure in colleges and universities [J] .China Light Industry Education, 2013,04: 5-7 + 19. 
[5] Zuo Jianmin, Wang Zhihua. Analysis of the program setting and order degree of the reform of the functional departments of colleges and universities[J]. Journal of Jiangsu Teachers College of Technology, 2011, 11: 1.

[6] Gao Yong. The construction of digital assets of financial assets under the reform of university system - Taking China University of Mining and Technology as an example[J]. Finance Monthly, 2015, 01: 22-24.

[7] Liu Yidong, Ren Liangyu.Technology and practical analysis of the reform of the large-scale system of teaching and research universities - Taking Inner Mongolia University as an example [J]. National Journal of Higher Education, 2015,03: 20-25.

[8] Li Han. Public sector organizational reform from the perspective of the reform of the university system - to D college reform practice as an example [J] .Chinese Journal of Qingdao Municipal Party School. Journal of Qingdao Administration College, 2015,04: 43-48.

[9] Fan Ping, Sun Pingping. On the "big system" reform in the internal management of colleges and universities [J]. Journal of Liaoning Administration College, 2013,11: 86-89. 